\title{
QUANTITATIVE EVALUATION OF THE SEISMICITY IN SEISMOGENIC SOURCES OF THE CIRCUM PACIFIC RIM
}

\author{
G.CH. KORAVOS ${ }^{1}$, T.M. TSAPANOS ${ }^{1}$, P.M. HATZIDIMITRIOU ${ }^{1}$ AND C.A. PAPAIOANNOU $^{2}$
}

\begin{abstract}
A quantitative measurement of the seismicity is undertaken along the seismogenic sources of the south and central America, as well as of Japan, Taiwan and Philippine islands. The mean return period, $\bar{T}$, is considered as measure of seismicity. For this purpose the whole process (method of mean value) and the part process (first asymptotic distribution of Gumbel's extreme values) techniques are adopted. The seismicity is evaluated for both shallow and intermediate focal depth shocks which occurred in the examined sources. The $a$ and $b$ values of the magnitude-frequency relationship are estimated for each source. The obtained results show that large welldefine zones of the mean return periods are dominated in the central and south America, while this is not so strong in the areas of Japan, Taiwan and Philippine islands, which probably due to the different tectonic setting of the areas (Tsapanos, 1990).
\end{abstract}

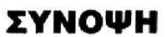

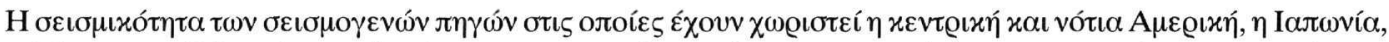

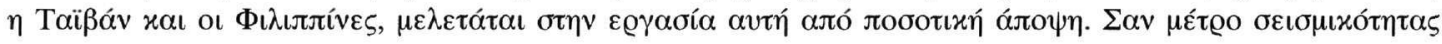

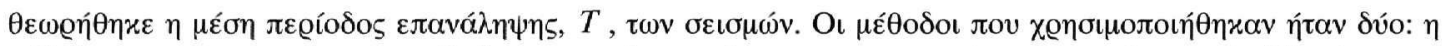

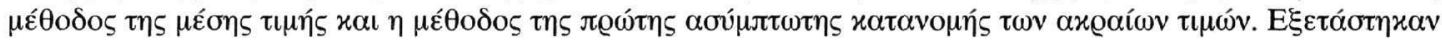

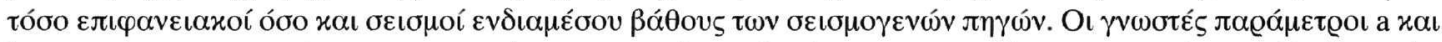

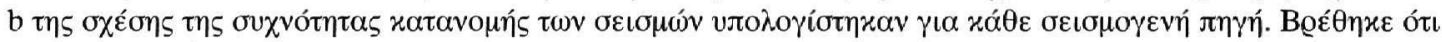

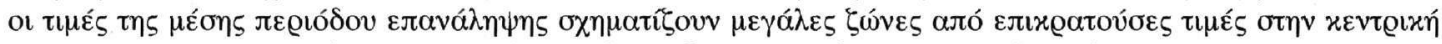

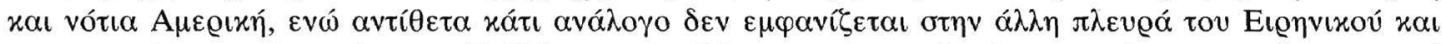

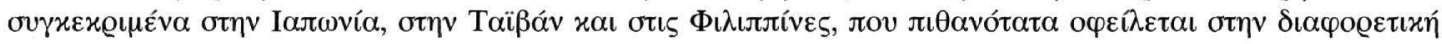

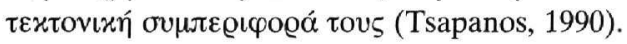

KEY WORDS: seimicity, mean return periods, Japan, Taiwan, Philippine, central and south America, method of mean value (M.M.V.), Gumbel (GI).

\section{INTRODUCTION AND METHOD APPLIED}

Quantitative methods have been applied over the last decades to estimate the seismicity of an area. Common methods used in these analyzes are the whole (method of mean value-M.M.V.) and the part $\left(\mathrm{G}^{\mathrm{I}}\right)$ processes. One of the ways for characterizing the seismicity of a region is through the study of its magnitude distribution in the time domain. The classical magnitude-frequency relationship suggested by Gutenberg and Richter (1944) is still the most commonly used:

$$
\log N_{k}=a_{k}-b M
$$

where $\mathrm{N}$, is the number of earthquakes greater or equal to $\mathrm{M}$ which occur in a region during a given time period in relation to their magnitudes, $\mathrm{M}$; and $\mathrm{k}$ is the number of years covered by the data sample. A large number of studies based on the well known Gutenberg-Richter's (whole process) parameters, $a$ and $b$ are published (Gutenberg and Richter, 1954; Papazachos et al., 1987; Hatazidimitriou et al., 1994; Tsapanos and Papazachos, 1998; Manakou and Tsapanos, 2000).

Alternatively, the first asymptotic distributions of extreme values of Gumbel (part process) have also proved

1. Aristotle University of Thessaloniki, School of Geology, Geophysical Laboratory, 54006 Thessaloniki, Greece.

2. I.T.S.A.K., P.O. Box 53 Foinikas, GR-55102 Thessaloniki, Greece. 
useful in evaluating the seismicity. The first asymptotic distribution of the extreme theory (Gumbel, 1958) is defined by:

$$
\boldsymbol{\Phi}^{\mathrm{I}}(\mathbf{M})=\exp (\exp (-\alpha(\mathrm{M}-\mathrm{u}))), \quad \mathbf{M}>0
$$

Several, out of many seismologists evaluated the seismicity through first asymptotic distribution which has the advantage that it does not require analysis of the whole data set (Epstein and Lomnitz, 1966; Yegulalp and Kuo, 1974; Makropoulos, 1978; Burton, 1979; Papaioannou, 1984; Tsapanos and Burton, 1991; Boomer et al., 1998). Epstein and Lomnitz (1966) assuming a Poisson distribution for the number of earthquakes with magnitudes exceeding zero in a year, found that the largest annual earthquake magnitude is distributed with the following cumulative distribution function:

$$
\mathrm{G}(\mathrm{M})=\exp [-\alpha \exp (-\beta \mathrm{M})], \mathbf{M} \geq 0
$$

where $\mathbf{G}(\mathbf{M})$ is the probability that an earthquake magnitude is $\mathbf{M}$ or lesser in a year.

The expected time interval for occurrence of one earthquake with magnitude greater or equal to $\mathrm{M}$ is defined as the mean return period, $T$ (in years), which is given by:

a) whole process $T=\frac{1}{N}$

and b) part process $T(M)=\frac{1}{1-\Phi(M)}$

where $[1-\Phi(M)]$ is the probability that an earthquake magnitude will be exceeded. The equations (4 and 5) are used in order to compute the quantitative seismicity of the seismogenic sources in which Japan, Taiwan, Philippine, central and south America are pre-divided (Papazachos et al., 1997). In figure (1) the seismogenic sources and the epicenters of earthquakes considered for the present study are depicted.

\section{THE DATA SET}

The fundamental requirement of the earthquake catalogue used in such studies is that it ought to be complete and homogeneous, that is, the data set must include all earthquakes of a certain time period with magnitudes larger than a certain cut off value and the magnitudes must be in the same magnitude scale, respectively. Moreover the data used must be accurate and have a rather big number of events. In order to obtain data which fulfill the predefined conditions we used all the available global catalogues (Tsapanos et al., 1990; Pacheco and Sykes, 1992; Abe 1994. In order to enrich our data set with more data the I.S.C. bulletins considered, for the time span 1991-1996. The accuracy of each catalogue is given, and the homogeneity is fulfilled by the acceptance of the surface magnitude $\left(\mathrm{M}_{\mathrm{s}}\right)$ scale. So we have to deal carefully with the completeness because the sample of each source is not complete, due to various reasons. Several tests are performed to check the completeness of the data, for several time periods, on the basis of the cumulative frequency distribution of the magnitude $M_{s}$, and the cumulative time distribution of the number of earthquakes with magnitudes larger than a certain value (Tsapanos and Papazachos, 1998). The completeness of some selected source is listed in Table (1), as an example. Our data cover a time span of 103 years (1894-1996).

In order to increase the number of data used in each time period and extend the curve derived from equation (1) to lower magnitudes, the frequencies of the magnitude for which the sample is not complete have been reduced to the interval of 103 years. In order to accomplish this procedure we follow the equation:

$$
V_{k}=V \frac{K}{K_{i}} \quad \mathrm{i}=1,2,3,4
$$

where $V$ is the number of earthquakes with magnitude $M$, which are observed during a time span of $K_{i}$, years and $V_{k}$, is the reduced number of the shocks for another time period $K$ which is the total number of years for which data are available (103 for our case). 
TABLE 1. The completeness obtained and used in order to evaluate the seismicity of the examined sources. The completeness, of the corresponding sources of figure (2), is listed.

SA-7

1899-1996, $M \geq 7.0$

1963-1996, $\mathrm{N} \geq 6.4$

1980-1996, $M \geq 5.5$
J-5

1895-1996, MD7.1

1930-1996, M 6.7

1956-1996, M $\geq 6.0$

1983-1996, M $\mathrm{D} 5.5$
PH-17

1903-1996, M $\geq 7.0$

1957-1996, M $\mathbb{2} 6.0$

1965-1996, M $\geq 5.5$
DCA

1911-1996, $\mathrm{M} \geq 7.0$

1937-1996, $M \geq 6.5$

1955-1996, $M \geq 6.0$

Conditions are considered in order to check the reliability of the results. These are: a) the difference between the maximum and the minimum magnitude in the data set is greater than or equal to 1.4 (Papazachos, 1974); b) the number of [LogN-M]pairs must be 5 or larger (Hatzidimitriou et al., 1994) and c) missing years (only for $\mathrm{G}^{\mathrm{I}}$ method) must be $<25 \%$ of the total entries (Burton, 1979). In figure(2a)we plot the LogN against M (through M.M.V), while in figure (2b) we plot (using the $G^{I}$ method) the $\log (-\ln G$ ) versus $M$, for some seismogenic sources.

\section{RESULTS AND DISCUSSION}

We check first how sensitive are the b-values obtained by both methods. For this purpose we plot (fig. 3) the difference between the b-values estimated by whole and part processes (M.M.V.- $\mathrm{G}^{\mathrm{I}}$ ) against the corresponding seismogenic sources. The sources 1 to 41 belong to shallow shocks, while the rest sources represent the intermediate events. Individual large differences are observed for some sources, but the mean, of all calculated differences (separately shallow and intermediate), is negligible. Then we examined separately the $b$ and the a values deduced from M.M.V. and $G^{\mathrm{I}}$ methods. In Figures $4(\mathrm{a}$ and $\mathrm{b}$ ) we plot the $\mathrm{b}$ and the a values estimated from $G^{\mathrm{I}}$ against M.M.V. Circles represent the observations of the sources (both shallow and intermediate), while with rhombus we illustrate the mean of $\mathrm{b}$ and a values with a step 0.1 and 0.5 , respectively. As it is shown in both figures the least square lines of the means of $b$ and a coincided with the mean line $Y=X$. The dash line shows the least square line of the individual observations. These lines (figs. $4 \mathrm{a}$ and $4 \mathrm{~b}$ ) show a trend that the values derived by $\mathrm{G}^{\mathrm{I}}$ technique are underestimated in comparison with those obtained through the method of the mean value.

We apply then the equations (5 and 6) in order to obtain the mean return periods of the seismogenic sources. As we previously mentioned we used this quantity as a quantitative measure of seismicity. The results are grouped in 4 categories. We computed the mean return periods for both magnitudes $M \geq 6.5$ and $M \geq 7.5$. The seismic sources in which the examined areas (Central and South America, Japan-Taiwan and Philippine islands) are divided, based on various criteria, taken from Papazachos et al. (1997). We believe that the shape of the seismogenic sources does not influence much the obtained seismicity results. On the other hand, this can affect the seismic hazard estimators. We observed (fig. 5a) that either for magnitude $\mathrm{M} \geq 6.5$ or $\mathrm{M} \geq 7.5$, from M.M.V.,

large zones of same estimates, which are clearer in central and south America with small $T$ values (lower to 5 years), which means sources of high seismicity. On the other hand in Japan, Taiwan and Philippine islands (fig.

$5 b$ ) we can inspect values of $T$ within the interval (group) 5 to 10 years, although a number of exceptions exists. Another observation for magnitudes $M \geq 7.5$ in this area reveals that some of the sources are empty, which means that either the largest observed magnitude is lower than 7.5, or this is due to the fact that for estimating

the value $(T$ or $\mathrm{T}(\mathrm{M}))$. We dealt with data coverage which are lesser than the return period of large earthquakes. Recurrence time of such large earthquakes ranges between 130-400 years (Rikitake, 1976; Nishenko, 1991; Scholz, 1994). We see that the observed pattern and particularly the one for erathquakes with magnitude $M \geq 7.5$, is in good aggreement with the results obtained by Tsapanos and Papazachos (1998). We then follow the same procedure for the $G^{1}$ method. The general pattern for central and south America is almost the same in comparison with M.M.V. Large zones $(\mathrm{M} \geq 6.5)$ with values between 5 to 10 years covered almost the whole south America, but also different groups (values lower than 5, 10 to 20 years, as well as lower than 35 years)

observed (fig.6a). Well-defined zones of same $\bar{T}$ (different from those evaluated before) are also formed when we dealt with $M \geq 7.5$. In figure (6b) the sources of Japan, Taiwan and Philippines are depicted. We can't ob-

served any clear pattern for both magnitudes examined, $M \geq 6.5$ and $M \geq 7.5$. Sources of different $\bar{T}$ values are mixed demonstrated in this way zones of low or/and high seismicity. 


\section{REFERENCES}

ABE, K. (1994). Instrumental magnitudes of historical earthquakes, 1892 to 1898, Bull. Seismol. Soc. Am., 84, 415-425.

BOOMER, J., McQUEEN, C., SALAZAR, W., SCOTT, S. and WOO, G. (1998). A case study of the spatial distribution of seismic hazard (El Salvador), Nat. Hazards, 18, 145-166.

BURTON, P.W. (1979). Seismic risk in southern Europe through to India examined using Gumbel's third distribution of extreme values, Geophys. J. R. Astr. Soc., 59, 249-280.

EPSTEIN, B. and LOMNITZ, C. (1966). A model for the occurrence of large earthquakes, Nature, 211, 954-956.

GUMBEL, E.J. (1958). Satistics of extremes, Columbia Univ. Press, N.Y., 375pp.

GUTENBERG, B. and RICHTER, C.F. (1944). Frequency of earthquakes in California, Bull. Seismol. Soc. Am., $34,185-188$.

GUTENBERG, B. and RICHTER, C.F. (1954). Seismicity of the earth and associated phenomena, Princeton Univ. Press, Princeton, N.Y., 310pp.

HATZIDIMITRIOU, P.M., PAPAZACHOS, B.C. and KARAKAISIS, G.F. (1994). Quantitative seismicity of the Aegean and surrounding area, Proc. XXIV Gen. Assem. ESC, Athens, Greece, 19-24 September 1994, vol. 1, 155-164.

MAKROPOULOS, K.C. (1978). The statistics of large earthquakes magnitude and an evaluation of Greek seismicity, Ph.D. Thesis, Univ. of Edinburgh, Edinburgh, 193pp.

MANAKOU, M.V. and TSAPANOS, T.M. (2000). Seismicity and seismic hazard parameters evaluation in the island of Crete and the surrounding area inferred from mixed data files, Tectonophysics, 321, 157-178.

NISHENKO, S.P. (1985). Circum-Pacific seismic potential, 1989-1999, Pageoph, 135, 169-259.

PACHECO, J.F. and SYKES, L.R. (1992). Seismic moment catalog of large shallow earthquakes, 1900 to 1989, Bull. Seismol. Soc. Am., 82, 1306-1349.

PAPAIOANNOU, Ch. A. (1984). Attenuation of seismic intensities and seismic hazard assessment in Greece and the surrounding area, Ph.D. Thesis, Univ. of Thessaloniki, Thessaloniki, 200pp. (In Greek with English abstract).

PAPAZACHOS, B.C. (1974). Dependence of the seismic parameter b on the magnitude range, Pageoph, 112, 1059-1065.

PAPAZACHOS, B.C., PPAPADIMITRIOU, E.E., KIRATZI, A.A., PAPAIOANNOU, Ch. A. and KARAKAISIS, G.E. (1987). Probabilities of occurrence of large earthquake in the Aegean and surrounding area during the period 1986-2006, Pageoph, 125, 597-612.

PAPAZACHOS, B.C, PAPADIMITRIOU, E.E, KARAKAISIS, G.F. and PANAGIOTOPOULOS, D.G. (1997). Long-term Earthquake prediction in the circum-Pacific convergent belt, Pageoph, 149, 173-217.

RIKITAKE, T. (1976). Recurrence of great earthquakes at subduction zones, Tectonophysics, 35, 335-362.

SCHOLZ, C.H. (1994). The mechanics of earthquakes and faulting, Cambridge Univ. Press, 439pp.

TSAPANOS, T.M. (1990). b-values of two tectonic parts in the circum-Pacific belt, Pageoph, 134, 229-242.

TSAPANOS, T.M. and BURTON P.W. (1991). Seismic hazard evaluation for specific seismic regions of the world, Tectonophysics, 195, 153-169.

TSAPANOS, T.M. and PAPAZACHOS, B.C. (1998). Geographical and vertical variation of the earth's seismicity, J. Seismology, 2, 183-192. 



Fig. 1. Geographical distribution of the epicenters of: a) shallow earthquakes in central and south America; b) intermediate depth events in the same area; $c$ ) shallow earthquakes in Japan-Taiwan-Philippines; and d) intermediate depth shocks in the same area. The borders of the sources are also depicted. 

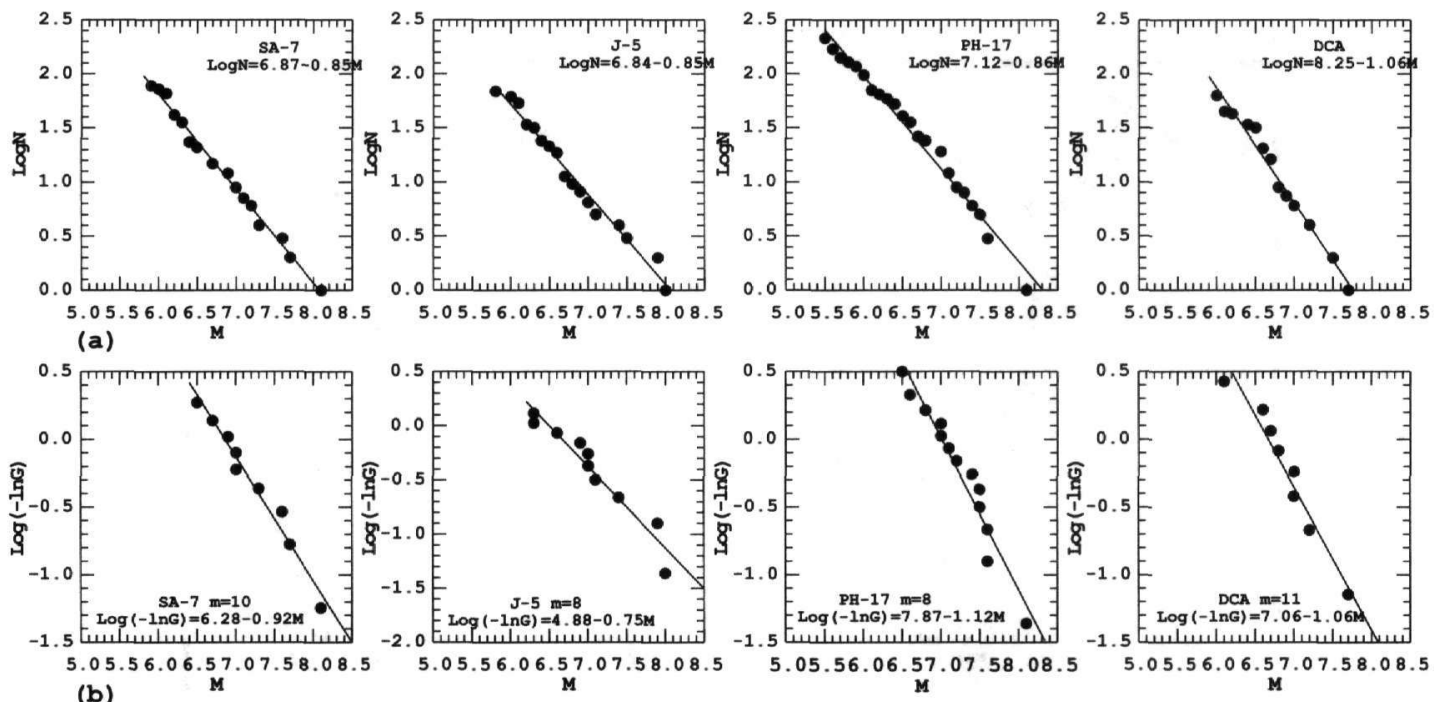

Fig.2. The frequency-magnitude distribution for three sources of shallow and one of intermediate focal depths. a) Gutenberg-Richter law (plot of LogN-M) and b) Gumbel (I) distribution [Log(-InG)-M].

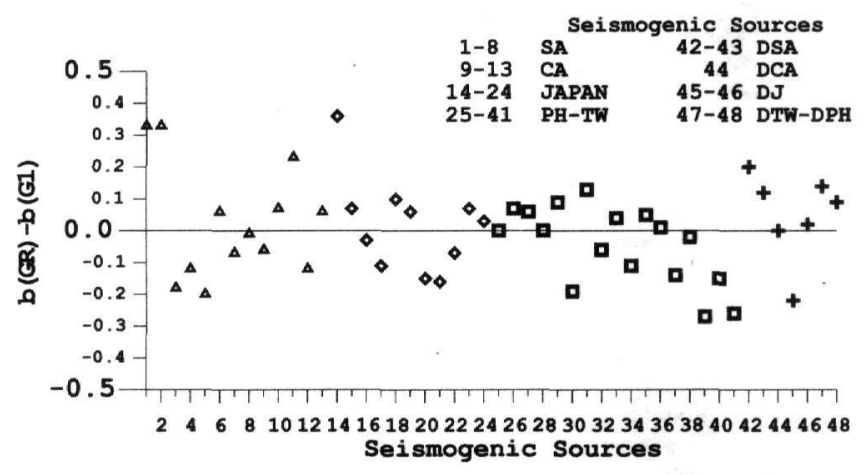

Fig.3. The difference of $b$ values (M.M.V-GI) versus the seismogenic sources. Source 1 to 41 belong to shallow depth shocks, while 42 to 48 belong to intermediate depth events.
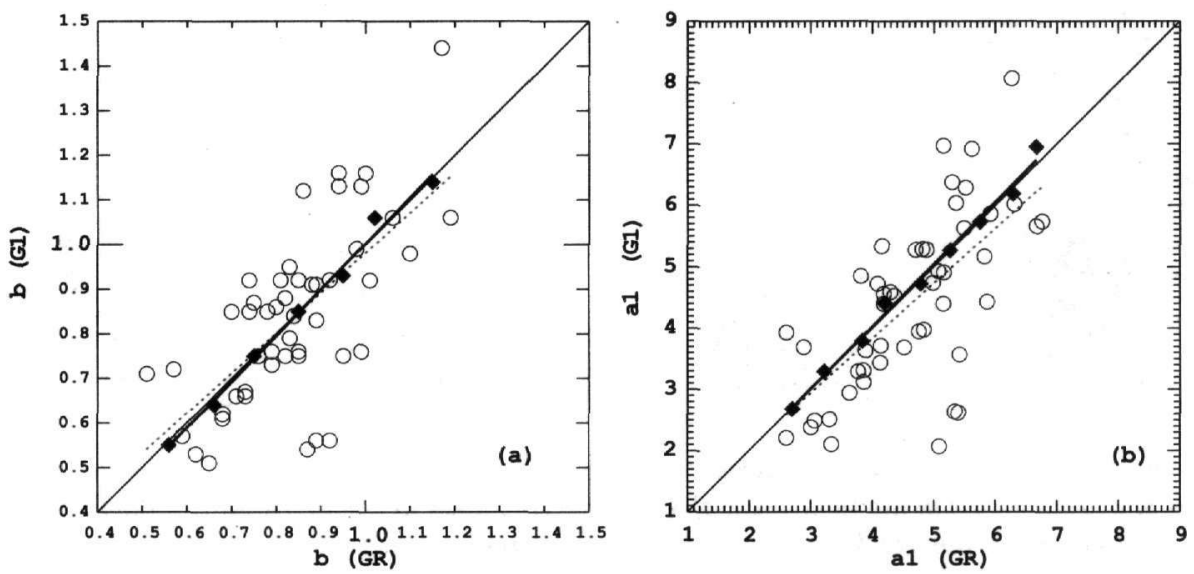

Fig.4. Plot of (a): b-values estimated by both methods and (b) a-values obtained by the application of both methods. The least square lines of the means $b$-values and a-svalues coincided with the mean line $Y=X$. 


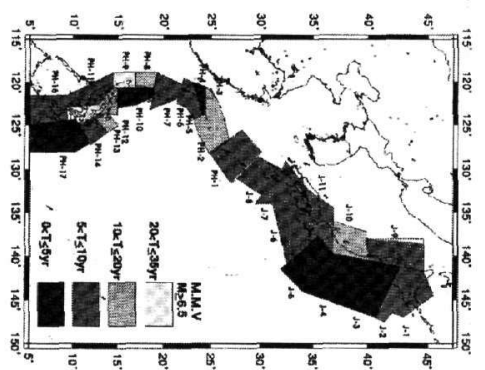

$\bar{\sigma}$

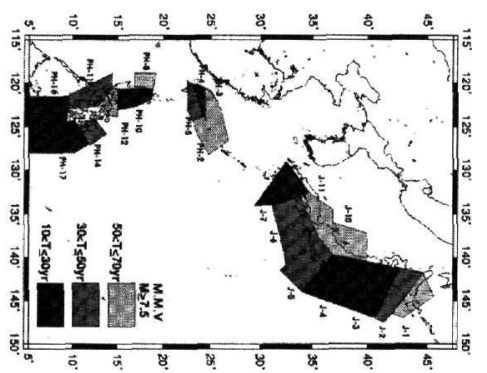

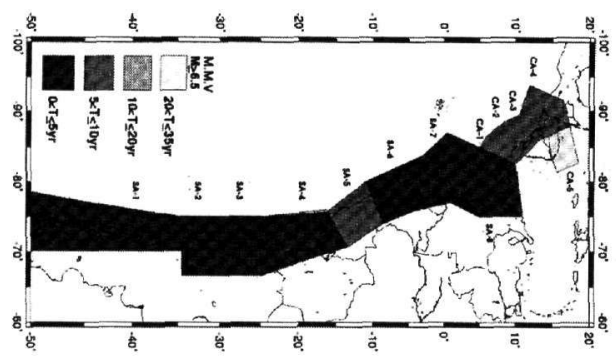

อ

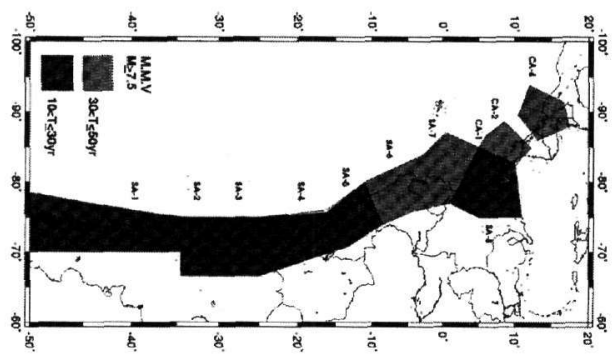

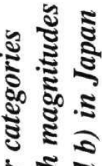

ฐิ

इ

ป

ํํㄹ ₹

. ป ะี

D

ฐ ฐ

范

ฐ

วิ

ริ

इ

डิ ฐิ

落

ค.

6.

o 5

造

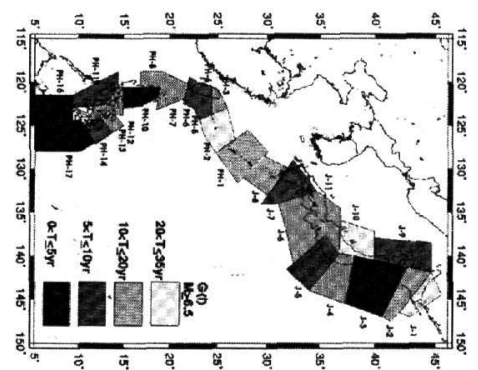

Eิ

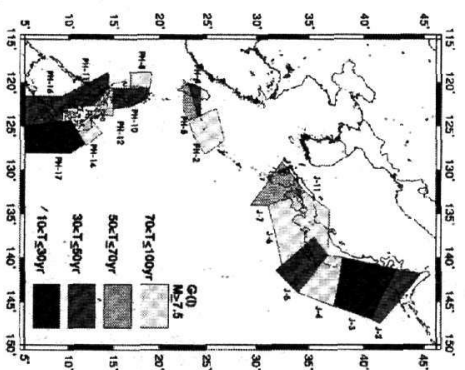

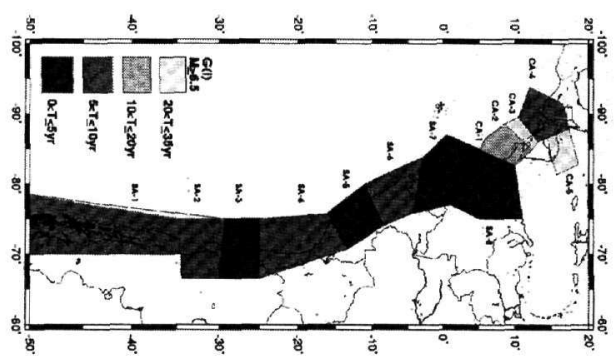

อ

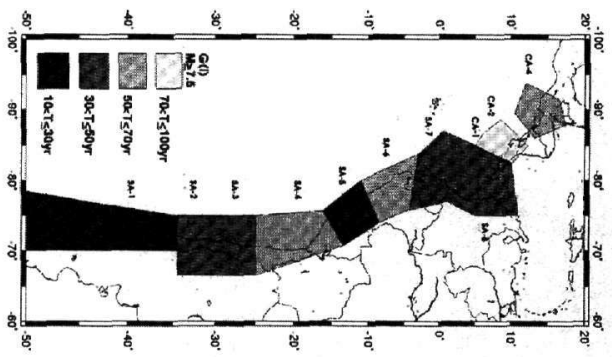

- 1513 -

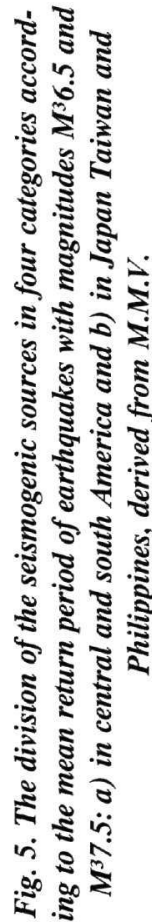

की 